\title{
The proteome of the heterocyst cell wall in Anabaena sp. PCC 7120
}

\author{
Suncana Moslavac', Veronika Reisinger'2, \\ Matthias Berg'3 ${ }^{3}$ Oliver Mirus', Oliver Vosyka1, \\ Matthias Plöscher ${ }^{2}$, Enrique Flores ${ }^{4}$, Lutz A. \\ Eichacker $^{2}$ and Enrico Schleiff ${ }^{1, *}$
}

\author{
${ }^{1}$ Department of Biology I, VW-Research Group, \\ LMU Munich, Menzinger Str. 67, D-80638 München, \\ Germany \\ ${ }^{2}$ Department of Biology I, LMU Munich, Menzinger Str. \\ 67, D-80638 München, Germany \\ ${ }^{3} \mathrm{M}-\mathrm{Scan} \mathrm{GmbH}$, Engesserstr. 4a, D-79108 Freiburg, \\ Germany \\ ${ }^{4}$ Instituto de Bioquímica Vegetal y Fotosíntesis, CSIC- \\ Universidad de Sevilla, Avda. Américo Vespucio 49, \\ E-41092 Sevilla, Spain \\ * Corresponding author \\ e-mail: schleiff@|rz.uni-muenchen.de
}

\begin{abstract}
Anabaena sp. PCC 7120 is a filamentous cyanobacterium that serves as a model to analyze prokaryotic cell differentiation, evolutionary development of plastids, and the regulation of nitrogen fixation. The cell wall is the cellular structure in contact with the surrounding medium. To understand the dynamics of the cell wall proteome during cell differentiation, the cell wall from Anabaena heterocysts was enriched and analyzed. In line with the recently proposed continuity of the outer membrane along the Anabaena filament, most of the proteins identified in the heterocyst cell-wall fraction are also present in the cell wall of vegetative cells, even though the lipid content of both membranes is different.
\end{abstract}

Keywords: Anabaena; $\beta$-barrel protein prediction; heterocyst; outer membrane; proteome analysis.

\section{Introduction}

The filamentous cyanobacterium Anabaena sp. PCC 7120 represents a model system for genetic and physiological studies of nitrogen fixation and prokaryotic cell differentiation (Wolk et al., 1984). When fixing $\mathrm{N}_{2}$, the filament is composed of two different cell types, vegetative cells that host a thylakoid membrane system and perform oxygenic photosynthesis, and heterocysts that fix $\mathrm{N}_{2}$. This cyanobacterium is also a model system for investigations of plastid evolution (Ertel et al., 2005; Bredemeier et al., 2007) because the gene content of plastomes is more closely related to bacteria of the genus Nostoc, e.g., Anabaena sp. PCC 7120, than to bacteria of the genus Synechocystis, e.g., Synechocystis sp. PCC 6803 (Martin et al., 2002). Generally, cyanobacterial cells are surrounded by two membranes, the plasma membrane and the outer membrane (Stanier and Cohen-Bazire, 1977). These are 30-40 $\mathrm{nm}$ apart and separated by the peptidoglycan layer. Recently it was suggested that in filamentous cyanobacteria the outer membrane is continuous along the filament (Flores et al., 2006), whereas the plasma membrane surrounds individual cells. The heterocyst cell wall carries an envelop that is external to the outer membrane and is composed of an inner glycolipid layer and an outer polysaccharide layer (Adams, 2000; Flores et al., 2006). The inner laminated layer, built of special glycolipids (hgl, heterocyst glycolipid), surrounds the outer membrane of the heterocyst and represents the actual barrier for gases. The layer consisting of heterocyst-specific polysaccharides (hep, heterocyst envelope polysaccharide) surrounds the laminated layer.

Based on the observed continuity of the outer membrane, metabolite exchange between vegetative cells and heterocysts through the periplasmic space was proposed (Flores et al., 2006). The consequence of this notion is a physiologically active periplasm, with major proteomic differences expected in the plasma membrane of the two cell-types. However, the formation of the heterocyst-specific glycolipid and polysaccharides layer (Adams, 2000) suggests a cell-type specific change in the outer membrane as well. Therefore, an outer membrane continuum raises several important questions: How are the specific glycolipids restricted to heterocysts? Are lipids or proteins of the outer membrane exchangeable between the cells of the filament? Is the outer membrane proteome of the two different cell-types comparable? To explore the latter question, the cell wall properties of vegetative cells and heterocysts have to be compared. As a first step, the proteome of vegetative cells of Anabaena sp. PCC 7120 was analyzed (Moslavac et al., 2005a). We then fractionated isolated heterocysts and analyzed the cell wall to develop a biochemical tool to investigate the adaptation after cell differentiation. We subsequently compared the lipid distribution and protein content of the two membranes and discuss the consequences.

\section{Results}

\section{Isolation of cell wall fractions from heterocysts}

First, we aimed to established nOmp85 (Alr2269; Ertel et al., 2005; Moslavac et al., 2005b; Bredemeier et al., 2007) as a cell wall-marker for both heterocysts and vegetative cells, because no heterocyst-specific outer membrane protein is known to date. nOmp85 was found in vegetative cells (Ertel et al., 2005) and the gene is expressed independently of the nitrogen source, as determined by microarray analysis (Ehira and Ohmori, 2006). The protein 
contains a classical targeting signal for translocation via the Sec translocon (Moslavac et al., 2005a). The NMPalr2269-GFP strain encodes nOmp85 with a C-terminal green fluorescent protein (GFP) attached by a GATatcCAT linker. Analysis of the GFP fluorescence (Figure 1, GFP and overlay) indicates that nOmp85 is present in both vegetative cells (Figure 1; identified by autofluorescence) and heterocysts (Figure 1; identified in bright field image). The ring-like fluorescence (Figure 1, enlargement) confirms the presence of GFP on the periphery of the cell, which is consistent with an outer membrane localization. However, the cell wall localization results in a weak fluorescence signal. For this reason, the GFP signal is only obtained in the focal plane and not in cells out of focus, as found for the cyanobacterial autofluorescence (Figure 1). The outer membrane localization of the protein was confirmed by Western blot analysis (data not shown). This observation confirmed the suitability of the use of nOmp85 antibodies for the quality control of heterocyst membranes.

Next, heterocysts were isolated by destruction of vegetative cells (Golden et al., 1991) of filaments (Figure 2A, heterocysts visualized by Alcian blue staining) grown for $48 \mathrm{~h}$ in $\mathrm{BG} 11_{0}$. The isolation of heterocysts was initially confirmed by microscopy (Figure 2B). The proteome of isolated heterocysts and vegetative cells differed significantly, as documented by SDS-PAGE analysis (Figure 2C, lanes 1 and 2), supporting the purity of the heterocyst fractions. Furthermore, heterocysts contain a modified inner membrane system that lacks components of the oxygen-evolving photosystem II, such as D1 (Baier et al., 2004). Immunodecoration of isolated vegetative cells and heterocysts with D1 antibodies (Figure 2C; lane 1, 2 bottom) confirmed the absence of this protein in the heterocyst fraction and thus the purity of these cells. Analysis of the lipid content of cells grown on BG11 or BG11。 (Figure 2D, lane 1,2) and isolated heterocysts (Figure 2D,

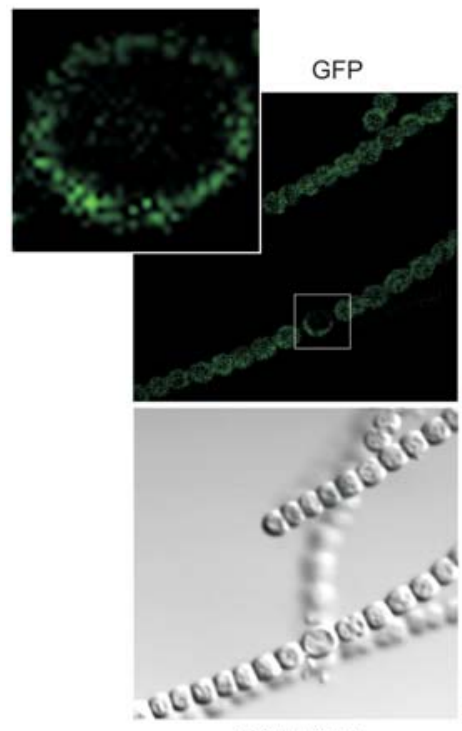

Bright field
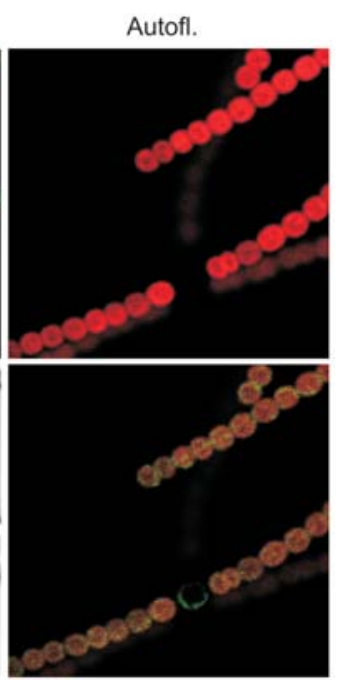

Overlay

Figure 1 Expression of an Alr2269-GFP fusion.

GFP signal, autofluorescence, bright field image and overlay analysis of strain NMP-alr2269-GFP. One heterocyst signal is enlarged (left-upper corner).
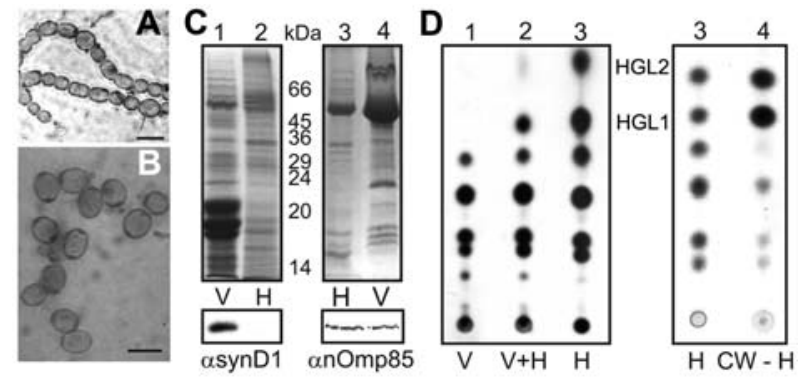

Figure 2 Heterocyst and heterocyst cell wall isolation.

(A) Filaments of Anabaena sp. PCC 7120 grown in BG11, were stained by Alcian blue and visualized by light microscopy. The scale indicated represents $5 \mu \mathrm{m}$. (B) Isolated heterocysts were analyzed by light microscopy after Alcian blue staining. The scale indicated represents $5 \mu \mathrm{m}$. (C) Samples (10 $\mu \mathrm{g}$ of protein) of vegetative cells (lane 1), heterocysts (lane 2), cell wall of heterocysts (lane 3 ) or cell wall of vegetative cells (lane 4) were subjected to SDS-PAGE, followed by Coomassie Blue staining or immunodecoration with D1 (lanes 1 and 2; bottom) or nOmp85 antibodies (lanes 3 and 4; bottom). (D) The lipid content in vegetative cell (lane 1), entire filament (lane 2), heterocyst (lane 3) and heterocyst cell wall fraction (lane 4) was analyzed. HGLs are indicated.

lane 3) documented the enrichment of the heterocystspecific glycolipids (HGL1 and HGL2).

For fractionation of the nitrogen-fixing cells, isolated heterocysts were broken by extensive sonication because they remain intact during mild treatment (Figure 2B). After fractionation, the cell wall fraction was isolated, as monitored by immunoassay with nOmp85-specific antibodies (Figure 2C, lanes 3 and 4; bottom). The protein content of the cell wall is largely comparable to that of the cell wall of vegetative cells (Figure 2C, lanes 3 and 4) although a few different bands are observed. Comparison of the lipids present in heterocysts (Figure 2D; lane 3) and in the cell wall fraction of heterocysts (Figure 2D; lane 4) shows enrichment of the heterocyst-specific glycolipids in the cell wall fraction. We therefore conclude that we have isolated a cell wall fraction of heterocysts.

\section{Analysis of the proteome}

The proteomic composition of different heterocyst cellwall fractions was analyzed using two strategies: peptide mass fingerprint analysis and peptide sequencing (Tables 1 and 2). For comparison, cell wall fractions prepared from vegetative cells were analyzed as well (Table 1, column 6 , a). A total of 18 proteins could be identified in the fraction from heterocysts, 13 of which were also identified in the cell wall fraction of vegetative cells (Table 1). The function and localization of these proteins were previously discussed (Moslavac et al., 2005a). However, the remaining five proteins might represent heterocyst-specific proteins. Indeed, NifH2 (Table 1, protein 17) is likely, as NifH (Elhai and Wolk, 1990), a heterocyst-specific protein, and the level of NtcA (Table 1, protein 4) is enhanced in heterocysts compared to vegetative cells (OlmedoVerd et al., 2005). However, both proteins likely represent cytosolic contamination. All1427 (Table 1, protein 15) contains two cystathionine- $\beta$ synthase domains (CBS), which are usually in tandem repeats and are found in 
Table 1 Proteins identified in the outer membrane fraction of heterocysts.

\begin{tabular}{|c|c|c|c|c|c|c|c|}
\hline No. & $\begin{array}{l}\text { Accession } \\
\text { number }\end{array}$ & Predicted function & Exp. & Peptides & $\begin{array}{l}\text { Found } \\
\text { in VC }\end{array}$ & $\begin{array}{c}\text { Mol. mass } \\
(\mathrm{kDa}) \\
\text { pre/mat }\end{array}$ & Up-regulation \\
\hline 1 & alr4550 & Probable porin & MF/PS & $21(173) / 12$ & $a / b$ & $60.5 / 57.8$ & - \\
\hline 2 & all4499 & Probable porin & MF/PS & $22(173) / 9$ & $a / b$ & $58.5 / 55.4$ & - \\
\hline 3 & alr0834 & Porin & MF/PS & $13(88) / 5$ & $-/ \mathrm{b}$ & 54.3 & + \\
\hline 4 & alr4392 & Nitrogen-responsive regulatory protein NtcA & PS & 6 & $-/-$ & 24.9 & + \\
\hline 5 & alr2269 & nOmp85 & PS & 8 & $-/ b$ & $89.5 / 87.8$ & - \\
\hline 6 & alr0397 & Similar to ferric aerobactin receptor & PS & 7 & $-/ \mathrm{b}$ & $94.2 / 90.2$ & - \\
\hline 7 & all3984 & Predicted protein & MF/PS & $12(108) / 4$ & $-/ b$ & $24.7 / 21.0$ & + \\
\hline 8 & alr5055 & Hypothetical protein & PS & 3 & $-/-$ & 21.6/19.02 & + \\
\hline 9 & alr2887 & Outer membrane efflux protein & MF/PS & $11(85) / 3$ & $a / b$ & $80.7 / 78.0$ & + \\
\hline 10 & all1861 & Peptidoglycan-binding protein & MF/PS & $12(90) / 4$ & $a / b$ & 28.4/27.1 & + \\
\hline 11 & all3585 & Hypothetical protein & MF/PS & $7(69) / 3$ & $\mathrm{a} / \mathrm{b}$ & $29.4 / 25.7$ & - \\
\hline 12 & all0089 & Hypothetical protein & MF/PS & $6(65) / 3$ & $-/ \mathrm{b}$ & 55.8 & + \\
\hline 13 & all0268 & Predicted $\mathrm{Zn}$-dependent hydrolases & MF/PS & $5(57) / 2$ & $-/ \mathrm{b}$ & $27.3 / 24.2$ & - \\
\hline 14 & all4388 & Involved in polysaccharide export & MF/PS & $9(67) / 4$ & $-/ \mathrm{b}$ & $51.5 / 48.0$ & + \\
\hline 15 & all1427 & Hypothetical protein & PS & 3 & $-/-$ & 21.6 & + \\
\hline 16 & alr0668 & Hypothetical protein & PS & 4 & $-/-$ & 23.0 & + \\
\hline 17 & alr0874 & Nitrogenase reductase $\mathrm{NifH} 2$ & PS & 3 & $-/-$ & 32.6 & + \\
\hline 18 & all3826 & $\begin{array}{l}\mathrm{N} \text {-Acetylmuramoyl-L-alanine amidase cwlL } \\
\text { precursor-like }\end{array}$ & PS & 3 & $-/ b$ & $25.4 / 22.3$ & - \\
\hline
\end{tabular}

Data presented are ORF numbers (column 2; Kaneko et al., 2001), predicted function (column 3), experiment in which the protein was detected (column 4; MF, mass fingerprint; PS, peptide sequencing), number of peptides detected (column 5) and detection score for MF, detection in cell wall of vegetative cells here (a) or previously (b) (Moslavac et al., 2005a; column 6), molecular mass (column 7), and significant up-regulation of gene expression (column 8; according to Ehira and Ohmori, 2006).

cytosolic and membrane proteins with diverse functions (Ignoul and Eggermont, 2005). Alr5055 (Table 1, protein 8) contains a domain found in proteins involved in spore germination. It was speculated that the homolog of Alr5055 in Bacillus subtilis, GerM, has a role in peptidoglycan synthesis during sporulation (Slynn et al., 1994). For Alr0668 (Table 1, protein 16), no significant homology to a protein or domain could be identified.

We next analyzed the five heterocyst-specific proteins for putative membrane localization using bioinformatics programs. Helical membrane segments could not be identified by TMHMM (data not shown). Next, we compared predictions by Signal P (Bendtsen et al., 2004), PSort (Gardy et al., 2005), our own program based on the $\beta$-barrel score (BBS275; Mirus and Schleiff, 2005), MCMBB (Bagos et al., 2004a) and Pred-TMBB (Bagos et al., 2004b; data summarized in Table 2). For comparison, we show the results for nOmp85, a protein clearly localized in the outer membrane (Figure 1). The results confirm the cytosolic localization of NifH2 and NtcA (Table 2) and suggest a cytosolic localization of the CBS-containing protein All1427. The localization of Alr5055 (protein 8) and Alr0668 (protein 16) is not reliably predictable. The presence of a secretion signal (Table 2) and the selection by two programs favors Alr5055 as being localized or attached to the outer membrane. For Alr0668, only our program suggests a $\beta$-barrel fold, except for the $0 \%$ false-prediction method (Table 2), which also suggests that Alr0668 is soluble.

When expression of the genes encoding the identified proteins was inspected according to Ehira and Ohmori (2006), we found that nine genes belong to the class induced as a starvation response or up-regulated during proheterocyst formation and four to the class specific for heterocysts (Figure 3; Ehira et al., 2003), considering the significance of the changes obtained. For alr2887 this up-regulation was independently observed by analyzing expression in the T22 mutant (Maldener et al., 2003). Most of the cytosolic proteins identified (3 out of 4) belong to the latter group. Remarkably, the genes encod-

Table 2 Predicted localization of proteins not identified in the cell wall of vegetative cells and of Alr2269.

\begin{tabular}{|c|c|c|c|c|c|c|c|c|c|}
\hline No. & Acc. no. & Signal P 3.0 & Loc & BBS275 & dep/ind. & $0 \%$ & MCMBB & Pred-TMBB & Fina \\
\hline 5 & alr2269 & ANA-QT (18) & OM & 2.79 & + & + & 0.033 & 19 & OM \\
\hline 15 & all1427 & - & Cyt & 0.03 & - & - & -0.038 & - & - \\
\hline 16 & alr0668 & - & Cyt & 1.37 & + & - & -0.031 & - & $?$ \\
\hline
\end{tabular}

Data presented are ORF numbers (column 2), putative cleavage site (column 3; Bendtsen et al., 2004), Psortb classification (column 4; Gardy et al., 2005), $\beta$-barrel score 275 (column 5; Mirus and Schleiff, 2005), selection by the dependent/ independent (column 6; Mirus and Schleiff, 2005) or $0 \%$ false-prediction method (column 7; Mirus and Schleiff, 2005), MCMBB score for mature proteins (selection >0; column 8; Bagos et al., 2004a) and number of transmembrane $\beta$-strands predicted by Pred-TMBB (column 9; Bagos et al., 2004b). Column 10 shows the final conclusion (cyt, cytosol; PP, periplasm; -, no selection/prediction; ?, no reliable prediction possible). 


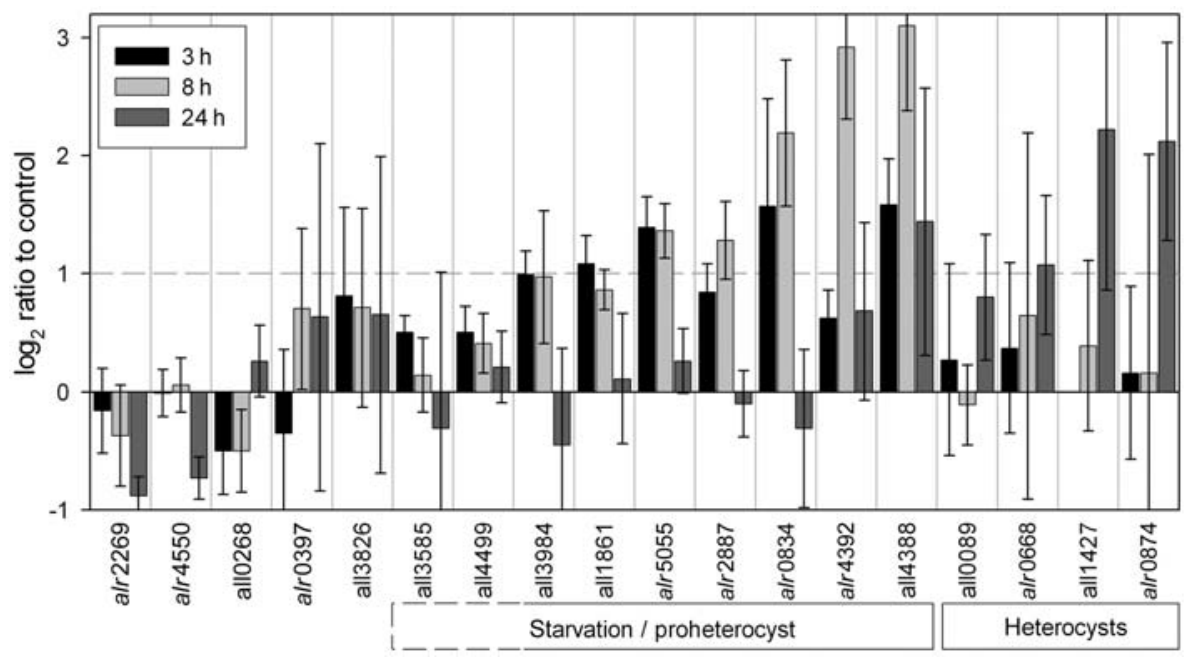

Figure 3 Expression of genes encoding proteins identified in the heterocyst outer membrane fraction.

$\log _{2}$ ratio of expression at indicated times after nitrogen step-down in comparison to untreated cells. Values are taken from Ehira and Ohmori (2006). Classification into the three groups is according to Ehira et al. (2003) and the gray dashed line shows the twofold change range.

ing Alr2269 and Alr4550 are down-regulated upon nitrogen step-down (Figure 3). However, these two proteins were among the most abundant in vegetative cells (Moslavac et al., 2005a) and down-regulation of their gene expression does not preclude the appearance of these proteins. Analysis of the expression of the genes coding for the $\beta$-barrel outer membrane proteins identified in proteomic analysis of vegetative cells but not of heterocysts shows that four genes are up-regulated. However, only two genes, all4026 and alr2588, showed significant up-regulation after $24 \mathrm{~h}$. Nevertheless, the analysis of gene regulation was performed using entire filaments (Ehira and Ohmori, 2006) containing approximately tenfold more vegetative cells than heterocysts (Adams, 2000). Hence, this analysis supports the idea of functional modification of the outer membrane proteome, but does not exclude the possibility that some of the changes in gene expression observed occur in vegetative cells rather than in heterocysts.

\section{Discussion}

A GFP fluorescence signal was obtained on the periphery of the cells with the Alr2269-GFP fusion analyzed in this work. Although the fluorescence signal was relatively weak, this observation is fully consistent with the location of Alr2269 in the outer membrane (Ertel et al., 2005; Moslavac et al., 2005b; Bredemeier et al., 2007). Because Alr2269 bears a signal peptide for export through the Sec translocation system, which is known to hardly render active GFP in the periplasm (Feilmeier et al., 2000; Thomas et al., 2001), weak fluorescence might result from poor maturation of GFP in the periplasm of the cyanobacterium. It is thought that disulfide bond formation during protein folding in the periplasmic space of non-filamentous bacteria causes the inactivation of GFP fluorescence. Hence, it might be suggested that the reducing capacity in the periplasmic space of Anabaena sp. PCC 7120 is different from that of non-filamentous bacteria. This notion is in line with a more active meta- bolic role in Anabaena than in other bacteria (Flores et al., 2006) requiring a different environment or a higher concentration of chaperones to allow significant folding of GFP. Alternatively, Alr2269 might be massively exported so that some GFP molecules fold properly, as GFP folds within seconds (Jackson et al., 2006). Nonetheless, it appears that folding of a Sec-translocated GFP takes place in the periplasm of Anabaena.

Using D1 as a marker for vegetative cells (Baier et al., 2004) and Alr2269 as a marker protein for outer membrane fractions (Figure 1; Ertel et al., 2005), we developed a protocol to isolate cell wall fractions from the nitrogen-fixing heterocysts. Approximately $50 \%$ of the proteins identified can clearly be assigned as outer membrane proteins, which is similar to the value previously reported for preparation of the cell wall fraction of vegetative cells (Moslavac et al., 2005a). All outer membrane proteins, with the possible exception of Alr5055, were identified in the cell wall of vegetative cells, suggesting similar proteome functionality of the two regions of the continuous outer membrane. In contrast, proteins with a highly probable cytosolic localization are not found in vegetative cell preparations and are products of genes up-regulated during nitrogen starvation (Figures 3 and 4; Ehira and Ohmori, 2006).

Although we cannot exclude the possibility that some proteomic alterations might have escaped our analysis, no significant amount of heterocyst-specific outer membrane proteins seems to exist, which is in line with continuity of the outer membrane along the filament (Flores et al., 2006). The difference in the number of proteins observed in cell wall fractions from vegetative cells (Moslavac et al., 2005a) and heterocysts (Table 1) could support the notion that not all outer membrane proteins of the heterocyst cell wall were identified, as large-scale mass spectrometry approaches favor the detection of abundant and non-hydrophobic proteins (Eichacker et al., 2004) and is dependent on the methodology used (Moslavac et al., 2005a). Alternatively, this observation might point to a higher diversity of the outer membrane proteome of vegetative cells. However, it cannot be 


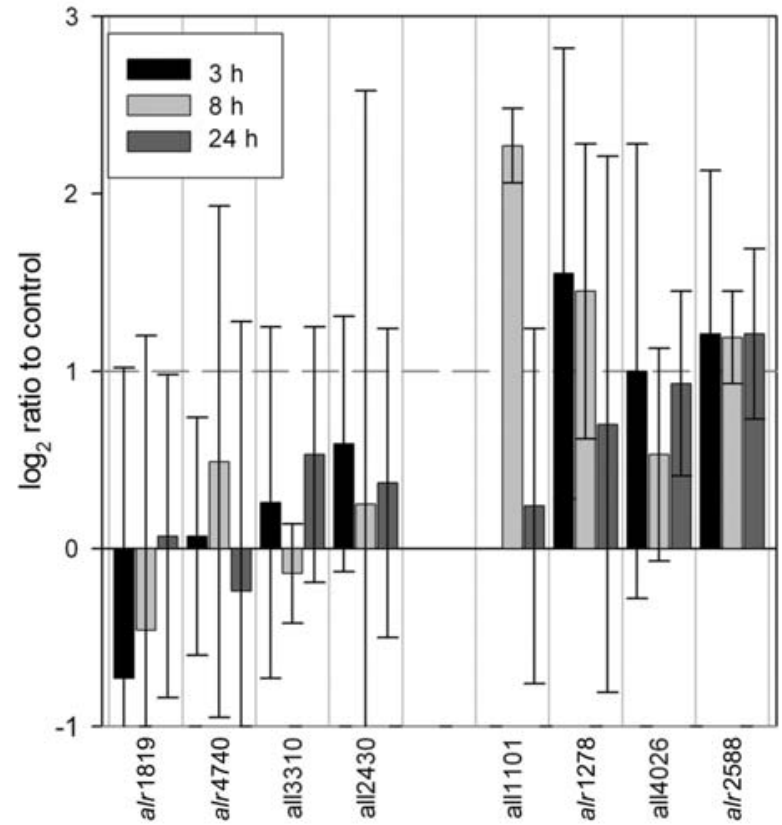

Figure 4 Expression of genes encoding outer membrane proteins identified in the outer membrane fraction of vegetative cells.

$\log _{2}$ ratio of expression at indicated times after nitrogen stepdown in comparison to untreated cells for genes encoding for outer membrane-inserted $\beta$-barrel proteins identified in Moslavac et al. (2005a). Values are taken from Ehira and Ohmori (2006). The gray dashed line shows the two-fold change range.

excluded that the cell wall fraction of vegetative cells was contaminated by heterocysts, as heterocyst induction could have occurred as a result of cyanobacterial growth in a dense culture. However, heterocysts show low abundance when filaments are grown in the presence of $\mathrm{NO}_{3}^{-}$ and are robust against the solubilization strategy used for vegetative cells (Figure 2). In addition, up-regulation of the expression of genes coding for outer membrane proteins, resulting in increased protein levels during heterocyst formation, might be an alternative to the insertion of novel proteins to regulate the functionality of the outer membrane (Table 1, Figures 3 and 4). For instance, the presence of the Omp85 homolog Alr2269 in the outer membrane of both cell types has been experimentally confirmed (Ertel et al., 2005; Bredemeier et al., 2007; Figure 1). Furthermore, the involvement of gene products in proheterocyst or heterocyst formation (e.g., alr4388; Maldener et al., 2003) does not necessarily imply that the protein has no function in vegetative cells, even though this function might not be essential. HetR, for example, seems to be essential for heterocyst differentiation (Herrero et al., 2004), but is also expressed in nitrate-grown cells (Ehira and Ohmori, 2006). However, the presence and function of gene products essential for heterocyst development in vegetative cells has to be confirmed in the future.

\section{Materials and methods}

\section{Bacterial strains and culture conditions}

Segments of $500 \mathrm{bp}$ of the alr2269 open reading frame encoding the C-terminus of the Alr2269 protein were amplified from genomic DNA of Anabaena sp. PCC 7120 (also termed Nostoc sp. PCC 7120) by PCR using primers with Clal/EcoRV restriction sites (alr2269-Cterm-GFP-F, 5'-ATC GAT CGA TAC GGG AGA AGA TGA CTT ATT ACT AG-3'; alr2269-Cterm-GFP-R, 5'-ATC GGA TAT CAA ACC TTT CTC CAA TAC CGA AAT TGA T-3'). The restricted PCR product was cloned into pCSEL21 (Olmedo-Verd et al., 2006). The C-terminal GFP fusion construct generated was excised by restriction with EcoRI and cloned into pCSV3 (Olmedo-Verd et al., 2006) to yield pNMP-alr2269-GFP. The plasmid was transferred to Anabaena sp. PCC 7120 by conjugation (Elhai and Wolk, 1988) to generate the NMP-alr2269-GFP strain. Single recombinants were selected on the basis of $\mathrm{Sp} / \mathrm{Sm}$ resistance conferred by the C.S3 cassette.

Cyanobacteria were grown photoautotrophically at $30^{\circ} \mathrm{C}$ in BG11 medium under illumination at $70 \mu \mathrm{mol}$ photons $\mathrm{m}^{-2} \mathrm{~s}^{-1}$ and bubbling with air containing $1 \% \mathrm{CO}_{2}$. Vegetative cells were fractionated as previously described (Moslavac et al., 2005a). To induce heterocyst formation, cells were collected at approximately $25 \mu \mathrm{g}$ chlorophyll a ml-1, centrifuged at $3000 \mathrm{~g}$ for $10 \mathrm{~min}$ at room temperature, washed twice with $B G 11_{0}$ medium and further grown in nitrate-free BG11, medium.

\section{Heterocyst isolation and fractionation}

Heterocysts were isolated according to Golden et al. (1991). In brief, cells were collected by centrifugation (3000 g) after 48-h induction in BG11。 medium. The presence of heterocysts was assessed by microscopy. The pellet was resuspended in icecold $8 \%$ sucrose, 5\% Triton X-100, 50 mM EDTA, pH 8.0, 50 mM Tris/ $\mathrm{HCl}, \mathrm{pH} 8.0,1 \mathrm{mg} / \mathrm{ml}$ lysozyme, and vortexed vigorously for 2-3 min at room temperature. The suspension was mildly sonicated (Sonopuls sonifier; Bandelin Electronic, Berlin, Germany; MS73 tip; 3 min on ice) to break the vegetative cells. Heterocysts were collected by centrifugation at $3000 \mathrm{~g}$ for $5 \mathrm{~min}$ at $4^{\circ} \mathrm{C}$ and washed four times in $8 \%$ sucrose, $50 \mathrm{~mm}$ EDTA, pH 8.0, $50 \mathrm{~mm}$ Tris/ $\mathrm{HCl}, \mathrm{pH}$ 8.0. The fraction was assessed by $0.5 \%$ Alcian blue (50\% ethanol solution) staining.

Isolated heterocysts were resuspended in $5 \mathrm{~mm}$ HEPES/ $\mathrm{NaOH}, \mathrm{pH}$ 8.0, 1 mM phenylmethylsulfonyl fluoride (PMSF), sonicated five times on ice (2 min with a 10-min break) using a Branson 450 sonifier (Branson Ultrasonic Corp., Danburg, CT, USA; macro tip, output 5) followed by four French press (SLM Instruments Inc., Rochester, NY, USA) cycles at 1100 psi. The suspension was mixed with Complete Protease Inhibitor (Roche, Mannheim, Germany) and centrifuged at $15000 \mathrm{~g}$ at $4^{\circ} \mathrm{C}$ for $1 \mathrm{~h}$. The pellet was resuspended in $15 \mathrm{ml}$ of $55 \%$ sucrose solution, overlaid by $8 \mathrm{ml}$ of $40 \%$ sucrose, $3 \mathrm{ml}$ of $30 \%$ sucrose and $7 \mathrm{ml}$ of $10 \%$ sucrose solution in $20 \mathrm{~mm}$ HEPES, pH 8.0, $0.2 \mathrm{~mm} \mathrm{PMSF}$ and centrifuged at $130000 \mathrm{~g}$ at $4^{\circ} \mathrm{C}$ for $16 \mathrm{~h}$. The orange cellwall pellet was collected from the bottom (Omata and Murata, 1984), washed twice in $20 \mathrm{~mm} \mathrm{HEPES} / \mathrm{NaOH}, \mathrm{pH} 8.0,1 \mathrm{~mm}$ PMSF, resuspended in the same buffer, frozen in liquid nitrogen and stored at $-20^{\circ} \mathrm{C}$. Lipid analysis is described in Fiedler et al. (1998).

\section{Microscopic visualization of protein localization}

Fluorescent imaging of the NMP-alr2269-GFP strain was performed on a TCS SP2 Leica confocal microscope (Wetzlar, Germany; HCX PLAN-APO $63 \times 1.4 \mathrm{NA}$ oil immersion objective). GFP was excited using the $488-\mathrm{nm}$ line of an argon ion laser and GFP fluorescence was analyzed in the window $500-570 \mathrm{~nm}$, while autofluorescence was monitored at $630-700 \mathrm{~nm}$ (MuroPastor et al., 2006).

\section{Digestion of cell wall proteins and mass spectrometric analysis}

Cell wall fractions were centrifuged at $80000 \mathrm{~g}$ for $10 \mathrm{~min}$ at $4{ }^{\circ} \mathrm{C}$. The pellet was resuspended in $80 \%$ acetone, $5 \%$ formic 
acid and $0.1 \%$ deoxycholic acid and incubated on ice for $10 \mathrm{~min}$. After centrifugation at $80000 \mathrm{~g}$ for $15 \mathrm{~min}$ at $4^{\circ} \mathrm{C}$, the pellet was washed with $20 \mu \mathrm{l}$ of $80 \%$ acetone and pelleted again by centrifugation for $10 \mathrm{~min}$. The pellet was resuspended in $100 \mathrm{~mm}$ Tris $/ \mathrm{HCl}, \mathrm{pH} 8.5,1 \mathrm{mM} \mathrm{CaCl}, 10 \mu \mathrm{g} / \mu \mathrm{l}$ trypsin with an enzyme/substrate ratio of approximately 1:100. Probes were transferred into LoBind tubes (Eppendorf, Hamburg, Germany) and incubated for $16 \mathrm{~h}$ at $37^{\circ} \mathrm{C}$ with gentle shaking. Digestion was stopped by addition of formic acid (5\% final concentration). Preparations were submitted to peptide sequencing by mass spectrometric analysis and proteins were identified by mass fingerprinting (Schmitt et al., 2006) and peptide sequencing (Moslavac et al., 2005a)

\section{Acknowledgments}

Protein identifications by peptide mass fingerprinting were performed at the protein analysis unit (ZfP, Adolf Butenandt Institute, LMU Munich). We thank J. Meuerer for supplying D1 antibodies. The work was supported by grants from Deutsche Forschungsgemeinschaft (SFB-TR01, C1 and C7) to E.S. and L.E., from the Volkswagenstiftung to E.S., and from the Boehringer Ingelheim Fonds to S.M.

\section{References}

Adams, D.G. (2000). Heterocyst formation in cyanobacteria. Curr. Opin. Microbiol. 3, 618-624.

Bagos, P.G., Liakopoulos, T.D., and Hamodrakas, J.S. (2004a). Finding beta-barrel outer membrane proteins with a Markov chain model. WSEAS Trans. Biol. Biomed. 2, 186-189.

Bagos, P.G., Liakopoulos, T.D., Spyropoulos, I.C., and Hamodrakas, S.J. (2004b). A Hidden Markov Model method, capable of predicting and discriminating $\beta$-barrel outer membrane proteins. BMC Bioinformatics 5, 29.

Baier, K., Lehmann, H., Stephan, D.P., and Lockau, W. (2004). NblA is essential for phycobilisome degradation in Anabaena sp. strain PCC 7120 but not for development of functional heterocysts. Microbiology 150, 2739-2749.

Bendtsen, J.D., Nielsen, H., von Heijne, G., and Brunak, S. (2004). Improved prediction of signal peptides: SignalP 3.0. J. Mol. Biol. 340, 783-795.

Bredemeier, R., Schlegel, T., Ertel, F., Vojta, A., Borissenko, L., Bohnsack, M.T., Groll, M., von Haeseler, A., and Schleiff, E. (2007). Functional and phylogenetic properties of the pore forming $\beta$-barrel transporters of the Omp85 family. J. Biol. Chem. 282, 1882-1890.

Ehira, S. and Ohmori, M. (2006). NrrA, a nitrogen-responsive response regulator, facilitates heterocyst development in the cyanobacterium Anabaena sp. strain PCC 7120. Mol. Microbiol. 59, 1692-1703.

Ehira, S., Ohmori, M., and Sato, N. (2003). Genome-wide expression analysis of the responses to nitrogen deprivation in the heterocyst-forming cyanobacterium Anabaena sp. strain PCC 7120. DNA Res. 10, 97-113.

Eichacker, L.A., Granvogl, B., Mirus, O., Müller, B.C., Miess, C., and Schleiff, E. (2004). Hiding behind hydrophobicity. Transmembrane segments in mass spectrometry. J. Biol. Chem. 279, 50915-50922.

Elhai, J. and Wolk, C.P. (1988). Conjugal transfer of DNA to cyanobacteria. Methods Enzymol. 167, 747-754.

Elhai, J. and Wolk, C.P. (1990). Developmental regulation and spatial pattern of expression of the structural genes for nitrogenase in the cyanobacterium Anabaena. EMBO J. 9, 3379-3388.

Ertel, F., Mirus, O., Bredemeier, R., Moslavac, S., Becker, T., and Schleiff, E. (2005). The evolutionarily related beta-barrel poly- peptide transporters from Pisum sativum and Nostoc PCC7120 contain two distinct functional domains. J. Biol. Chem. 280, 28281-28289.

Feilmeier, B.J., Iseminger, G., Schroeder, D., Webber, H., and Phillips, G.J. (2000). Green fluorescent protein functions as a reporter for protein localization in Escherichia coli. J. Bacteriol. 182, 4068-4076.

Fiedler, G., Arnold, M., and Maldener, I. (1998). Sequence and mutational analysis of the $\operatorname{dev} B C A$ gene cluster encoding a putative $A B C$ transporter in the cyanobacterium Anabaena variabilis ATCC 29413. Biochim. Biophys. Acta 1375, 140143.

Flores, E., Herrero, A., Wolk, C.P., and Maldener, I. (2006). Is the periplasm continuous in filamentous multicellular cyanobacteria? Trends Microbiol. 14, 439-443.

Gardy, J.L., Laird, M.R., Chen, F., Rey, S., Walsh, C.J., Ester, M., and Brinkman, F.S. (2005). PSORTb v.2.0: expanded prediction of bacterial protein subcellular localization and insights gained from comparative proteome analysis. Bioinformatics $21,617-623$

Golden, J.W., Whorff, L.L., and Wiest, D.R. (1991). Independent regulation of nifHDK operon transcription and DNA rearrangement during heterocyst differentiation in the cyanobacterium Anabaena sp. strain PCC 7120. J. Bacteriol. 173, 7098-7105.

Herrero, A., Muro-Pastor, A.M., Valladares, A., and Flores, E. (2004). Cellular differentiation and the NtcA transcription factor in filamentous cyanobacteria. FEMS Microbiol. Rev. 28, 469-487.

Ignoul, S. and Eggermont, J. (2005). CBS domains: structure, function, and pathology in human proteins. Am. J. Physiol. Cell Physiol. 289, C1369-1378.

Jackson, S.E., Craggs, T.D., and Huang, J.R. (2006). Understanding the folding of GFP using biophysical techniques. Expert Rev. Proteomics 3, 545-559.

Kaneko, T., Nakamura, Y., Wolk, C.P., Kuritz, T., Sasamoto, S., Watanabe, A., Iriguchi, M., Ishikawa, A., Kawashima, K., Kimura, T., et al. (2001). Complete genomic sequence of the filamentous nitrogen-fixing cyanobacterium Anabaena sp. strain PCC 7120. DNA Res. 8, 205-213; 227-253.

Maldener, I., Hannus, S., and Kammerer, M. (2003) Description of five mutants of the cyanobacterium Anabaena sp. strain PCC 7120 affected in heterocyst differentiation and identification of the transposon-tagged genes. FEMS Microbiol. Lett. 224, 205-213.

Martin, W., Rujan, T., Richly, E., Hansen, A., Cornelsen, S., Lins, T., Leister, D., Stoebe, B., Hasegawa, M., and Penny, D. (2002). Evolutionary analysis of Arabidopsis, cyanobacterial, and chloroplast genomes reveals plastid phylogeny and thousands of cyanobacterial genes in the nucleus. Proc. Natl. Acad. Sci. USA 99, 12246-12251.

Mirus, O. and Schleiff, E. (2005). Prediction of $\beta$-barrel membrane proteins by searching for restricted domains. BMC Bioinformatics 6, 254.

Moslavac, S., Bredemeier, R., Mirus, O., Granvogl, B., Eichacker, L.A., and Schleiff, E. (2005a). Proteomic analysis of the outer membrane of Anabaena sp. strain PCC 7120. J. Proteome Res. 4, 1330-1338.

Moslavac, S., Mirus, O., Bredemeier, R., Soll, J., von Haeseler, A. and Schleiff, E. (2005b). Conserved pore-forming regions in polypeptide-transporting proteins. FEBS J. 272, 13671378.

Muro-Pastor, A.M., Olmedo-Verd, E., and Flores, E. (2006). All4312, an NtcA-regulated two-component response regulator in Anabaena sp. strain PCC 7120. FEMS Microbiol. Lett. 256, 171-177.

Olmedo-Verd, E., Flores, E., Herrero, A., and Muro-Pastor, A.M. (2005). HetR-dependent and -independent expression of heterocyst-related genes in an Anabaena strain overproducing the NtcA transcription factor. J. Bacteriol. 187, 1985-1991. 
Olmedo-Verd, E., Muro-Pastor, A.M., Flores, E., and Herrero, A. (2006). Localized induction of the ntcA regulatory gene in developing heterocysts of Anabaena sp. strain PCC 7120. J. Bacteriol. 188, 6694-6699.

Omata, T. and Murata, N. (1984). Isolation and characterization of three types of membranes from the cyanobacterium (blue green alga) Synechocystis sp. PCC 6714. Arch. Microbiol. 139, 113-116.

Schmitt, S., Prokisch, H., Schlunck, T., Camp, D.G. II, Ahting, U., Waizenegger, T., Scharfe, C., Meitinger, T., Imhof, A., Neupert, W., et al. (2006). Proteome analysis of mitochondrial outer membrane from Neurospora crassa. Proteomics 6, 72-80.

Slynn, G.M., Sammons, R.L., Smith, D.A., Moir, A., and Corfe, B.M. (1994). Molecular genetical and phenotypical analysis of the gerM spore germination gene of Bacillus subtilis 168 . FEMS Microbiol. Lett. 121, 315-320.

Stanier, R.Y. and Cohen-Bazire, G. (1977). Phototrophic prokaryotes: the cyanobacteria. Annu. Rev. Microbiol. 31, 225-274.

Thomas, J.D., Daniel, R.A., Errington, J., and Robinson, C. (2001). Export of active green fluorescent protein to the periplasm by the twin-arginine translocase (Tat) pathway in Escherichia coli. Mol. Microbiol. 39, 47-53.

Wolk, C.P., Vonshak, A., Kehoe, P., and Elhai, J. (1984). Construction of shuttle vectors capable of conjugative transfer from Escherichia coli to nitrogen-fixing filamentous cyanobacteria. Proc. Natl. Acad. Sci. USA 81, 1561-1565.

Received February 5, 2007; accepted March 29, 2007 